\title{
PENGARUH PERSEPSI HARGA DAN KUALITAS PRODUK TERHADAP NILAI PELANGGAN BATU KAPUR PADA CV. SALSABILLA GROUP DI GRESIK
}

\author{
Bagus Wahyudi Putra ${ }^{1}$, Tony Susilo Wibowo² \\ Universitas PGRI Adi Buana Surabaya ${ }^{1,2,3}$ \\ Bagusw608@gmail.com
}

\begin{abstract}
ABSTRAK
Tujuan dilakukukanya penelitian guna melihat sejauh mana Persepsi Harga maupun Kualitas Produk mempengaruhi Nilai Pelanggan Batu Kapur pada CV. Salsabilla Group. Populasi penelitian ini adalah semua pelanggan $\mathrm{CV}$. Salsabilla Group. dengan sampel 100 responden dan memakai incidental sampling. Semua data dikumpulkan melalui pembagian angket/kuesioner. dan selanjutnya dianalisa dengan bantuan Software IBM SPSS Version 22.

Hasil analisa menunjukkan (1) persepsi harga mempengaruhi nilai pelanggan batu kapur pada CV. Salsabilla Group, dengan menggunakan uji-t, dan didapat t-hitung dari persepsi harganya sebanyak 3.701 kemudian tingkat signifikansinya sebesar .000 . (2) kualitas produk mempengaruhi nilai pelanggan batu kapur CV. Salsabilla Group. Didapat t-hitung dari kualitas produknya sebanyak 4.217 sedangkan tingkat signifikansinya yaitu .000 . (3) Sedangkan baik persepsi harganya maupun kualitas produknya mempengaruhi dengan simultan ke nilai pelanggan batu kapur CV. Salsabilla Group. Pengujian ini

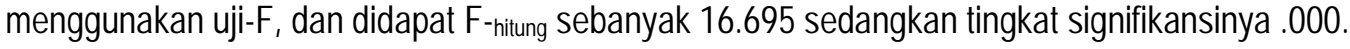

Kata Kunci : Persepsi Harga, Kualitas Produk, Nilai Pelanggan

\section{ABSTRACT}

The purpose of the research is to see the extent to which Price Perception and Product Quality affect Limestone Customers Value in CV. Salsabilla Group. The study population was all customers of CV. Salsabilla Group. with a sample of 100 respondents and using incidental sampling. All data is collected through questionnaire / questionnaire distribution. and then analyzed help by IBM SPSS Version 22 Software.

The results of the analysis show (1) price perception affects the value of limestone customers in the CV. Salsabilla Group, using t-test, and obtained t-count from the perception of the price of 3,701 then the significance level of .000. (2) product quality affects the value of limestone customers CV. Salsabilla Group. Obtained from the product quality counted 4,217 while the significance level was .000. (3) While both the perception of the price and the quality of the product affect simultaneously to the value of the limestone customer CV. Salsabilla Group. This test uses the F-test, and obtained an F-count of 16,695 while the significance level is .000 .

Keywords : Price Perception, Product Quality, Customer Value 


\section{PENDAHULUAN}

Generasi $Z$ industri di Negara Indonesia sudah maju mengikuti zaman, salah satunya industri dibidang produksi batu kapur. Batu kapur ialah sektor utama bahan dasar bangunan. Saat produksi batu kapur berkembang memakai teknologi dan konsumen meminta supaya kualitas batu kapur yang dijual baik dengan harga yang standart, alternatifnya adalah mencari strategi produksi yang baik agar hasil produknya berkualitas dengan persepsi harga yang bersaing,

Seperti halnya yang dengan apa yang dikatakan Paul dan Olson dalam Diana Yunita Sari, Dkk, (2018:679), beliau mengutarakan persepsi harga artinya pelanggan memahami informasi harga yang diberikan dari perusahaan yang bermakna untuk pelanggan dan dapat membayangkan penetapan harga di perusahaan lalu dievaluasi apakah harga tersebut cocok dengan tingkat kualitas produk yang diinginkan.

Tingkat kualitas produk di perusahaan ditentukan dengan tingkat seberapa puas pelanggan yang menggunakan produknya dari perusahaan itu. seberapa kuat produk supaya bisa memuaskan pelanggan/konsumennya saat menggunakan produk perusahaan itu. Jika apa yang dibutuhkan pelanggan sudah terpenuhi, pelanggan akan menilai dari output produk tersebut. (Cannon, Perreault, dan Mccarthy,2008).

Dengan demikian, dijelaskan oleh beberapa orang peneliti selalu menerangkan/menjelaskan tentang pengkombinasian dari harga maupun kualitas output produknya yang laku dipasaran. (Kotler bersama keller, 2009:14). Hal ini sangat diperhatikan oleh perusahaan CV. Salsabilla Group agar dapat menciptakan loyalitas pelanggan untuk mempertahankan usahanya dengan memperhatikan nilai pelanggan batu kapur yang ada di Gresik.

CV. Salsabilla Group adalah satu dari perusahaan yang bergerak dibidang produksi batu kapur yang bertempat di Desa Bolo, Kecamatan Ujungpangkah, Kabupaten Gresik, Jawa Timur. CV. Salsabilla Group saat ini memproduksi batu kapur yang sudah memakai teknologi moderen agar hasil dari produknya berkualitas. CV. Salsabilla Group saat ini produknya dipasarkan ke beberapa kota salah satunya Kota Gresik, Kota Lamongan, serta Kota Tuban. produksi batu kapur dengan pertumbuhan yang pesat, dapat menimbulkan persaingan ketat. Dengan demikian secara tidak langsung mendorong CV. Salsabilla Group untuk tetap mempertahankan pelanggannya memakai cara memperhatikan apa yang diinginkan pelanggannya supaya produk yang diperjualkan mempunyai rasa puas, baik dengan kualitas produknya maupun persepsi harganya yang normal sesuai visi dan misi perusahaan CV. Salsabilla Group.

Memperhatikan kondisi tersebut, penulis tertarik untuk membahasnya dimana judul yang penulis pilih "Pengaruh Persepsi Harga maupun Kualitas Produk Terhadap Nilai Pelanggan Batu Kapur Pada CV. Salsabilla Group".

Tujuan daripada penelitian tersebut. ialah guna mengetahui, (1) sejauh mana persepsi harga mempengaruhi nilai pelanggan batu kapur, (2) sejauh mana kualitas produk mempengaruhi nilai pelanggan batu kapur, (3) serta sejauh mana baik persepsi harga, maupun kualitas produk mempengaruhi nilai pelanggan batu kapur dengan cara simultan di CV. Salsabilla Group.

TINJAUAN PUSTAKA DAN HIPOTESIS 


\section{Pengertian Pemasaran}

Bagus dan Wisnu (2015:6) pemasaran adalah kegiatan menjalankan bisnis yang dilakukan oleh pemasar untuk memenuhi kebutuhan pasar supaya memuaskan konsumen dan mencapai tujuan perusahaan berupa barang dan jasa.

\section{Persepsi Harga}

Peneliti bernama Peter dan Olson dalam Harjati dan Yurike (2015:67) menuliskan pemikiran yang menyangkut persepsi harga yang artinya pemahaman konsumen atas informasi dari harganya yang ditawarkan akan diberikan arti yang penting dari brand tersebut. Dengan kata lain pelanggan bisa membedakan harganya yang di berikan oleh perushaan tersebut dan di kira-kira oleh pelanggannya. Adapun indikator persepsi harga yang ditulis dari Dwihapsari dalam Fuad (2016:16) meliputi :

1.keterjangkauan harganya.

2.Harganya selaras seperti produknya yang dihasilkan.

3.mengkombinasikan harganya dari competitor.

\section{Kualitas Produk}

Pentingnya suatu produk yang berkualitas maka perusahaan berlomba-lomba meningkatkan produknya supaya laku dipasaran. Untarini (2014:112) mengemukakan kualitas produk artinya kemampuan dalam memuaskan kebutuhan pelanggan yang bergantung pada karakteristik produk atau jasa.

Adapun indikator kualitas produk yang diidentifikasi dari Jakper et.al dalam Ningrum (2019:30) meliputi:

1.Ketahanan

2.Keselarasan

3.Kehandalan

4.Fasilitas dalam perbaikan

Nilai Pelanggan

Dalam dunia bisnis maupun industri pelanggan merupakan asset penting yang harus dijaga agar usaha dai perusahaan bisa tetap bertahan. Kotler maupun Keller (2013:147) menyebutkan nilai pelanggan artinya tanggapan pelanggan berkaitan dengan nilai yang mampu mempengaruhi tingkat loyalitas pelanggan. Dari kata lain, anggapan dari pembeli tentang bagaimana produknya yang dikeluarkan dari perusahaan itu bagus atau tidak dan keloyalitasannya dari pembeli tersebut tinggi.

Adapun indikator untuk mengukur nilai pelanggan yang disebutkan Yonggui et.al dalam Siti Munisih (2014:99) meliputi :

1.Pengorbanan

2.Emosional

3.Fungsional

\section{Kerangka Konseptual \& Hipotesis}


Berdasar dari uraian diatas, kerangka dari penelitian dapat digambarkan dibawah ini:

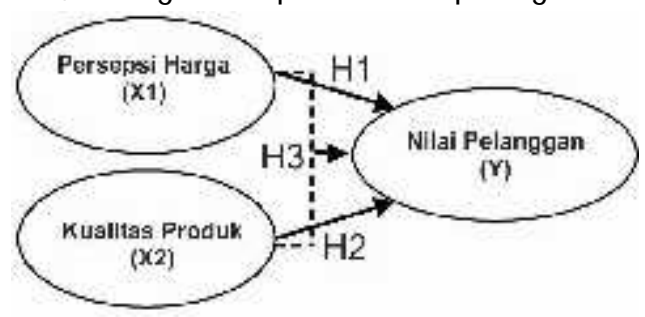

Gambar 1

Kerangka Konseptual

Dari kerangka konsep diketahui hipotesis yang diajukan oleh peneliti yaitu:

H1:Diduga adanya persepsi harga mempengaruhi nilai pelanggan batu kapur di CV. Salsabilla Group. H2:Diduga adanya kualitas produk mempengauhi nilai pelanggan batu kapur di CV. Salsabilla Group. H3:Diduga adanya persepsi harga maupun kualitas produk mempengaruhi bersama-sama ke nilai pelanggan batu kapur di CV. Salsabilla Group.

\section{METODE PENELITIAN}

Peneliti menggunakan metode kantitattif. Data yang didapat berdasar pembagian kuesioner ke pelanggan batu kapur CV. Salsabilla Group. Yang dianalisa statistic dan nantinya akan menjadikan jawaban dari hipotesis yang diajukan. Peneliti mengambil populasi seluruh pelanggan batu kapur. Akan tetapi peneliti mengambil sampling incidental sebagai teknik saat kuesioner dibagikan ke pelanggan di CV. Salsabilla Group. dan sampel berjumlah 100 pelanggan yang membeli batu kapur di CV. Salsabilla Group.

\section{Uji Validitas}

Pengujian validitas ini dipakai sebagai tolak ukur indikator penelitian. Valid maupun tidaknya indikator tersebut bisa melihat perbandingan antara $\mathrm{R}_{\text {hitung }}$ maupun $\mathrm{R}_{\text {tabel, }}$ bilamana $\mathrm{R}_{\text {hitung }}>\mathrm{R}_{\text {tabel }}$ artinya indikator tersebut valid dan begitu juga kebalikannya.

\section{Uji Reliabilitas}

Uji reliabilitas dilakukan guna menguji apakah indikator pada kuesioner tersebut dapat dipercaya atau tidak. Pengujian ini dikatakan reliabilitas bila ( $a$ ) lebih besar dari 0,60 begitupun juga sebaliknya.

\section{Analisis Regresi Linier Berganda}

Analisa ini sebagai teknik mengetahui sebarapa besar independent variable mempengaruhi dependent variable. Selain itu, juga alat untuk menguji adanya kebenaran atau tidaknya hipotesis yang dipakai atau diajukan dipenelitian. Rumus analisis regresi linier berganda:

\section{$Y=a+B 1 X 1+B 2 X 2+e$}

Ket:

$\mathrm{Y} \quad=$ Nilai Pelanggan

a $=$ Constanta

$\mathrm{B} 1, \mathrm{~B} 2=$ Koefisien regresi

$\mathrm{X} 1, \mathrm{X} 2$ =Independent Variable

$\mathrm{E} \quad=$ eror 


\section{Pengujian Hipotesis}

\section{Uji-t (Parsial)}

Penggunaan dari pengujian t yaitu guna mengetahui seberapa jauh mempengaruhi dari independent variable ke dependent variable dengan cara parsial.

Uji-t bisa dikatakan mempengaruhi apabila nilai sig $<0.05$.

\section{Uji-F (Simultan)}

Penggunaan dari pengujian $\mathrm{F}$ sebagai mengetahui seberapa jauh tingkat pengaruhnya dari kedua independent variable ke dependent variable dengan simultan.

Pengujian dikatakan mempengaruhi apabila tingkat signifikansi bernilai $<0.05$.

\section{HASIL DAN PEMBAHASAN}

\section{Perhitungan Uji Validitas}

Pengujian ini peneliti dibantu dengan Software IBM SPSS Statistic Version 22. Berikut adalah tabel 1 hasil dari pehitungan validitas :

Tabel 1

Hasil Uji Validitas

\begin{tabular}{|c|c|c|c|c|}
\hline \multirow[t]{2}{*}{ ariabel } & nyataan & Hitung & :Tabel & :erangan \\
\hline & .1.1_1 & 0,518 & & \\
\hline rsepsi & :1.1_2 & 0,613 & & \\
\hline larga & 1.21 & 0,427 & 0,196 & Valid \\
\hline \multirow[t]{5}{*}{ (X1) } & $1.2-2$ & 0,502 & & \\
\hline & 1.3 & 0,696 & & \\
\hline & :1.3_2 & 0,707 & & \\
\hline & .2 .11 & 0,666 & & \\
\hline & :2.1_2 & 0,742 & & \\
\hline 」alitas & $2.2 \_1$ & 0,748 & & \\
\hline roduk & .2.2_2 & 0,808 & 0,196 & Valid \\
\hline \multirow[t]{5}{*}{ (X2) } & 2.3_1 & 0,556 & & \\
\hline & $2.3-2$ & 0,704 & & \\
\hline & :2.4_1 & 0,725 & & \\
\hline & $2.4 \_2$ & 0,786 & & \\
\hline & Y.1_1 & 0,828 & & \\
\hline Nilai & Y.1_2 & 0,795 & & \\
\hline anggan & Y.2_1 & 0,696 & 0,196 & Valid \\
\hline \multirow[t]{3}{*}{$(Y)$} & Ү.2_2 & 0,814 & & \\
\hline & Y.3_1 & 0,378 & & \\
\hline & Y.3_2 & 0,478 & & \\
\hline
\end{tabular}

Sumber : Output SPSS, diolah 2020

Dari pengujian diatas disimpulkan bahwa hasil keseluruhan menunjukkan $R_{\text {hitung }}>R_{\text {tabel }}$ dan dinyatakan seluruh indikator kuesioner valid.

\section{Perhitungan Uji Reliabilitas}

Pengujian ini peneliti dibantu dengan Software IBM SPSS Statistic Version 22. Berikut adalah tabel 2 merupakan dari perhitungan reliabilitas:

Tabel 2

Hasil Uji Reliabilitas

\begin{tabular}{lll}
\hline Variabel & :h's Alpha (a) Kritis terangan \\
\hline
\end{tabular}




\begin{tabular}{llll}
\hline Harga (X1) & 0.602 & 6 & Reliabel \\
Produk (X2) & 0.866 & 6 & Reliabel \\
ınggan (Y) & 0.766 & .6 & Reliabel \\
\hline
\end{tabular}

Sumber : Output SPSS data diolah 2020

Dari hasil diatas menunjukkan seluruh variabel bernilai $(a)>0,60$, dan disimpulkan semua indikator yang digunakan reliabel.

\section{Hasil Analisis Regresi Linier Berganda}

Pengujian ini peneliti dibantu dengan Software IBM SPSS Statistic Version 22. Berikut tabel 3 merupakan perhitungan analisis regresi linier berganda.

Tabel 3

Hasil Uji Regresi Linier Berganda

\begin{tabular}{lcc}
\hline Variabel & \multicolumn{2}{c}{ Unstandardized } \\
& B & Std. Eror \\
\hline (Constant) & 6.318 & 2.899 \\
ersepsi Harga & 0.396 & 0.107 \\
ualitas Produk & 0.230 & 0.054 \\
\hline
\end{tabular}

Sumber : Output SPSS data diolah 2020

Dari tabel tersebut diketahui regresi yang terbentuk :

$$
Y: 6.318+0.396 \times 1+0230 X 2+e
$$

Keterangan :

a.Nilai konstanta a sebesar 6.318 .

b.Koefisien variabel X1 bernilai sebanyak 0.396 .

c.Koefisien variabel X2 bernilai sebanyak 0.230 .

\section{Uji Hipotesis}

Uji-t

Hasil pengujian ini peneliti dibantu menggunakan Software IBM SPSS Statistic Version 22 dan didapat hasill di tabel 4 sebagai berikut:

Tabel 4

Hasil Uji t

\begin{tabular}{ccc}
\hline Variabel & $\mathrm{t}$ & Sig. \\
\hline Persepsi Harga & 3.701 & 0.000 \\
Kualitas Produk & 4.217 & 0.000 \\
\hline
\end{tabular}

Sumber : Output SPSS data diolah 2020

Dari tabel tersebut terlihat tingkat signifikansinya dari variabel persepsi harga(X1) bernilai sebanyak $0,000<0,05$ maka bisa dikatakan $\mathrm{H}_{0}$ ditolak dari derajat kepercayaan $5 \%$, sedangkan $\mathrm{H} 1$ diterima dari derajat kepercayaan $5 \%$. yang berarti, variabel tersebut mempengaruhi nilai pelanggan $(\mathrm{Y})$. Tingkat signifikansi variabel kualitas produk $(\mathrm{X} 2)$ bernilai $0.000<0.05$. Jadi bisa dijelaskan $\mathrm{H}_{0}$ ditolak dari derajat kepercayaan $5 \%$ sedangkan $\mathrm{H} 1$ diterima dari derajat kepercayaan $5 \%$. yang berarti, variabel tersebut mempengaruhi terhadap nilai pelanggan $(\mathrm{Y})$.

Uji-F 
Hasil pengujian Uji-F peneliti dibantu dengan Software IBM SPSS Statistic Version 22. Berikut hasil perhitungan pengujian bisa dilihat berikut ini:

Tabel 5

Hasil Uji F

\begin{tabular}{ccc}
\hline & $\mathrm{F}$ & Sig. \\
Regression & 16.695 & $0.000^{\mathrm{b}}$
\end{tabular}

Sumber : Output SPSS data diolah 2020

Dari tabel 5 didapatkan $\mathrm{F}_{\text {-hitung }}$ sebanyak 16.695 dengan tingkat sig. $0.000^{\mathrm{b}}<0.05$. maka bisa dijelaskan $\mathrm{H}_{0}$ ditolak dari derajat kepercayaannya $5 \%$. sedangkan $\mathrm{H} 1$ diterima dari derajat kepercayaannya $5 \%$. Maka diartikan variabel kedua variabel independent tersebut mempengaruhi bersama/simultan terhadap nilai pelanggan $(\mathrm{Y})$.

\section{PEMBAHASAN}

\section{A. Hipotesis 1}

Dari hasil pengujian t didapatkan tingkat signifikansi persepsi harga bernilai $.000<0.05$. melihat hasil tersebut maka dijelaskan bahwa Independent Variabel X1 mempengaruhi Nilai Pelanggan ( $Y$ ) batu kapur pada CV. Salsabilla Group. Dari hasil ini diketahui semakin bagusnya persepsi harga yang diciptakan oleh perusahaan maka nilai pelanggan akan terjadi dan terbukti ada hubungannya.

\section{B. Hipotesis 2}

Hasil uji-t kualitas produk (X2) didapat tingkat signifikansinya bernilai .000<0.05. dilihat dari hasilnya, maka dijelaskan bahwa Kualitas Produk (X2) mempengaruhi Nilai Pelanggan $(Y)$ batu kapur pada CV. Salsabilla Group. Dengan hasil ini bahwa bisa dikatakan jika kualitas yang dihasilkan diperusahaan itu baik. dan produk-produknya bisa diterima oleh pelanggannya dengan puas dibuktikan dengan pengujian hipotesis yang bernilai $<5 \%$.

\section{C.Hipotesis 3}

Hasil uji-F didapat tingkat signifikansinya bernilai $0.000<0.05$. dilihat dari hasilnya, maka bisa dijelaskan dari kedua variabel bebas antara Persepsi Harganya (X1) maupun Kualitas Produknya (X2) mempengaruhi Nilai Pelanggan (Y) batu kapur pada CV. Salsabilla Group secara bersama (simultan) dan terbukti jika ada pengaruhnya.

\section{SIMPULAN}

Dari penelitian yang telah dilakukan, yaitu persepsi harga $(X 1)$ mempengaruhi nilai pelanggan $(Y)$ batu kapur diperusahaan CV. Salsabilla Group yang dibuktikan dengan tingkat signifikansi bernilai .000 . kualitas produk (X2) mempengaruhi nilai pelanggan (Y) batu kapur diperusahaan batu kapur CV. Salsabilla Group yang dibuktikan tingkat signifikansi bernilai .000. sedangkan baik persepsi harganya (X1) maupun Kualitas Produknya $(Y)$ mempengaruhi nilai pelanggan $(Y)$ yang dibuktikan tingkat signifikansinya bernilai $.000^{\mathrm{b}}$.

\section{IMPLIKASI}

Peran manajemen perusahaan sangat penting guna memotivasi karyawannya agar hasil dari produknya sangat berkualitas agar apa yang diharapkan dari pelanggan tersampaikan. Karena perusahaanya itu bisa dikatakan baik, apabila hasil produknya tersebut berkualitas, dan harganya yang dipatok atau di tawarkan dari CV. Salsabilla Group standart normal sesuai pasaran. Akan tetapi pelanggan 
bisa merasakan kualitas yang diberikan dari perusahaan tersebut, dipenelitian kali ini, peneliti melihat seberapa tingkat signifikansinya baik dari persepsi harganya maupun kualitas produknya dapat mempengaruhi nilai pelanggan batu kapur diperusahaan CV. Salsabilla Group. Maka dari itu, implikasi dari persepsi harganya maupun kualitas produknya agar ditingkatkan lagi melalui berbagai cara perusahaan menciptakan sebuah inovasi-inovasi ide-ide yang kreatif dan inovatif agar hasil dari produknya akan semakin berkualitas dengan kebutuhan yang diminta dari pelanggan bisa tercukupi dengan baik, dan terciptalah nilai pelanggan yang baik serta memuaskan baik dari perusahaan maupun pelanggan CV. Salsabilla Group sendiri.

\section{KETERBATASAN PENELITIAN}

a.Didalam penelitian yang dilakukan yaitu metode kuantitatif. Data berupa angka yang didapat dari item pernyataan dikuesioner yang diajukan peneliti. sehingga penelitian terbatasi oleh variabel tersebut.

b.Dipenelitian ini, peneliti hanya sebatas menguji beberapa faktor yang dapat dipengaruhii nilai pelanggan batu kapur pada CV. Salsabilla Group, yaitu dua variabel bebas dalam hal ini : persepsi harga maupun kualitas produk.

c.Jawaban yang diberikan oleh responden kadang kurang menggambarkan dengan keadaan lapangan yang sesungguhnya. Sehingga keterbatasan ini diharapkan untuk lebih diperhatikan bagi peneliti selanjutnya.

d.Pada saat penyebaran pernyataan yang ada dikuesioner dibarengi dengan wabah SARS CoV-2 sehingga tidak kondusif.

\section{DAFTAR PUSTAKA}

Bagus, I Made dan Sutama Wisnu, 2015. Manajemen Pemasaran. Adi Buana University Press. Diana Yunita Sari, Endang Tjahjaningsih, dan Kristina Anindita Hayuningtias, 2018. Pengaruh Kualitas 
Produk, Persepsi Harga, Promosi, dan Lokasi Terhadap Proses Keputusan Pembelian Kapur Barus Merek Bagus (Studi Pada Konsumen Giant BSB Semarang. Jurnal Prosiding SENDI_U ISBN: 978-9793649-99-3 halaman 679.

Fuad, Muhammad, 2016. Pengaruh Persepsi Harga, Kualitas Layanan, dan Citra Merek Terhadap Kepuasan Pelanggan Pada Pengguna Bus Trans Jogja Di Yogyakarta. Skripsi : Universitas Yogyakarta.

Kotler, Philip dan Keller, Kevin Lane 2009. Manajemen Pemasaran. Jakarta : Jilid 1. Edisi Ke 13 Erlangga. 2013. Manajemen Pemasaran. Jakarta : Jilid 2 Erlangga.

Harjati, Lily dan Yurike Venesia, 2015. Pengaruh Kualitas Layanan dan Persepsi Harga Terhadap Kepuasan Pelanggan Pada Maskapai Penerbangan Tiger Air Mandala. E-Journal Widya Ekonomika, Vol. 1, Nomor 1.

Ningrum, Mega Sulistyo, 2019. Pengaruh Harga, Kualitas Produk dan Citra Merek Terhadap Keputusan Pembelian (Studi Pada Konsumen Hisana Fried Chicken Di Kecamatan Candi, Sidoarjo). Skripsi Universitas PGRI Adi Buana Surabaya.

Siti Munisih, Euis Soliha, 2015. Pengaruh Kualitas Produk Terhadap Niali Pelanggan dan Kepuasan Pelanggan dan Dampaknya Pada Loyalitas Pelanggan Apotek Dela Semarang. Prosiding Seminar Nasional Dan Call For Paper. Universitas Stikubank Semarang.

Untarini, Nindria, 2014. Perilaku Konsumen. Unesa University Press.

Http://Ejournal-S1.Undip.Ac.Id/Index.Php/Dbr Volume 2, Nomor 2, Tahun 2013, Halaman 1 ISSN (Online): 2337-3792) (Diakses, 10 Oktober 2019. 